\title{
Fitur Reminder Angsuran Pinjaman Anggota Menggunakan Sms Gateway Pada Sistem Informasi Simpan Pinjam Berbasis Web Di KPRI Mitra Setia
}

\author{
Ai Musrifah ${ }^{1}$, Eneng Siti Sa'adah ${ }^{2}$ \\ Program Studi Teknik Informatika \\ Fakultas Teknik Universitas Suryakancana \\ aimusrifah.unsur@gmail.com,nengsitisaadah47@gmail.com
}

\begin{abstract}
Abstrak
KPRI Mitra Setia adalah koperasi yang sudah lama berdiri dari tahun 1930 sampai sekarang dan koperasi ini khusus untuk pegawai Negeri Kecamatan Cibeber, seiring meningkatnya permasalahan yang ada di KPRI Mitra Setia ini seperti pengelolaan simpan pinjam, semakin banyaknya data, sering terjadi keterlambatan pembayaran angsuran, dan perhitungan yang belum terkomputerisasi. Oleh karena itu di buat Fitur Reminder Angsuran Pinjaman Anggota Menggunakan Sms Gateway pada Sistem Informasi Simpan Pinjam Berbasis Web di KPRI Mitra Setia untuk mengurangi permasalahan yang muncul.

Dalam pembuatan aplikasi ini digunakan metoda pengembangan sistem berdasarkan paradigma Waterfall . Sedangkan untuk metode perancangan sistem menggunakan konsep perancangan terstruktur dimana menggunakan alat-alat perancangan seperti Use Case Diagram, Activity Diagram, Class Diagram dan Sequence Diagram. Bahasa pemograman yang digunakan untuk membangun aplikasi ini yaitu bahasa pemrograman php.

Sistem yang dirancang mempunyai kelebihan dalam mempermudah perhitungan proses pengelolaan data simpan pinjam dan dalam pencarian mengakses data mengenai simpan pinjam lebih mudah, serta aplikasi ini memberikan kemudahan kepada anggota untuk melihat langsung di web berapa simpanan uang yang masuk dan mempermudah mengingatkan tanggal jatuh tempo pembayaran angsuran kepada anggota.
\end{abstract}

\section{Kata Kunci : Sistem Informasi, Waterfall, Pengelolaan}

\section{Pendahuluan}

\subsection{Latar Belakang Masalah}

Suatu aplikasi dibuat untuk mempermudah pencatatan dan pemrosesan data tersebut dapat memberikan kemudahan pada pengelolaan data perusahaan, agar dalam pencatatan dan pemrosesan data lebih efektif dan lebih efisien. Dengan adanya sebuah aplikasi, data akan tersimpan secara komputerisasi dan akan lebih mudah diakses ketika data tersebut sedang dibutuhkan atau diperlukan. penyimpanan data yang sudah terkomputerisasi akan berpengaruh terhadap penyajian data, keamanan data, ke efisienan dan kemudahan dalam pencatatan, pengaksesan dan pemrosesan data. Sistem adalah suatu jaringan kerja dari prosedur-prosedur yang saling berhubungan, berkumpul bersama-sama untuk melakukan suatu kegiatan atau untuk menyelesaikan suatu sasaran yang tertentu (Jogiyanto, 2005:!). Informasi adalah data yang diolah menjadi bentuk yang lebih berguna dan lebih berarti bagi yang menerimanya (Jogiyanto. 2005:11). Sistem komputer telah banyak digunakan di dalam beberapa bidang seperti administrasi, perbankan, organisasi, instansi formal dan masih banyak lagi termasuk koperasi namun masih terdapat pula perusahaan maupun instansi yang masih minim dalam pemanfaatan teknoligi yang ada sehingga dapat memperlambat dan menghambat pekerjaan para pekerja. Selain itu semakin berkembangnya teknologi pada saat ini banyak pengunaan fitur remainder seperti sms gateway sebagai alat pengingat. Dalam jurnalnya
Andri Setyawan mengungkapkan bahwa sms gateway dapat digunakan untuk yang semakin mempermudah sebagai pengingat untuk jatuh tempo pembayaran angsuran pinjaman dan membantu dari kinerja pihak koperasi untuk memberi informasi kepada nasabah dalam melakukan angsuran dengan cepat tanpa mendatangi ke rumah nasabah.

Koperasi Mitra Setia merupakan koperasi khusus organisai untuk pegawai dinas pendidikan kecamatan Cibeber, yang menjadi anggota dan yang bisa menyimpan tabungan dan meminjam dari koperasi tersebut hanya pegawai khusus dinas pendidikan kecamatan Cibeber. Koperasi mitra setia beralamat di Jl. Cihaur No.3, Cihaur, Cibeber, Cianjur. Koperasi mitra setia memeiliki anggota yang semakin banyak yaitu dari lingkungan pendidikan mulai dari SD, SMP, SMA/SMK dan pegawai dinas lainnya yang ada di kecamatan cibeber. Dari semakin banyaknya anggota tersebut maka timbul masalah-masalah yang ada di koperasi tersebut seperti penumpukkannya data yang ada di koperasi tersebut karena masih di catat dalam buku besar belum terkomputerisasi, pada saat anggota akan menyimpan uang atau pada saat meminjam perhitungannya masih konvensional meskipun ada perhitungan di excel membutuhkan waktu yang lama karena menggunakan rumus, selain pada saat anggota ingin melihat uang yang sudah masuk untuk di simpan masih belum fleksibel karena untuk melihat data tersebut harus di lihat dari buku dan untuk mencari data dalam buku memerlukan waktu yang cukup lama karena semakin banyaknya data 
yang masuk. Maka dari itu para staf yang ada di koperasi tersebut sering kesulitan bila masalan-masalah tersebut ada dan penyimpanan data dalam buku yang tidak terjamin keamanannya karena bisa saja buku tersebut hilang dan lupa menyimpannya. Dan juga sering terjadi keterlambatan pada saat pembayaran angsuran pinjaman karena anggota koperasi lupa tanggal tempo pembayaran dan harus diingatkan oleh petugas koperasi pada saat anggota tersebut ada dilokasi.

Berdasarkan permasalahan di atas maka KPRI mitra setia harus mempunyai sistem pengolahan data simpan pinjam yang mampu melakukan pengolahan data simpan pinjam ssecara lebih mnyeluruh dan dapat mempermudah dalam pekerjaan yang ada di koperasi.

Diharapkan sistem tersebut mampu membantu staf yang ada di koperasi tersebut dan mempermudah dalam proses pengolahan data simpan pinjam yang ada di Koperasi Mitra Setia.

\subsection{Rumusan Masalah}

Berdasarkan latar belakang masalah di atas, maka yang menjadi rumusan masalah dalam pengerjaan penelitian yaitu bagaimana merancang fitur reminder angsuran pinjaman anggota menggunakan sms gateway pada sistem informasi simpan pinjam berbasis web.

\subsection{Maksud dan Tujuan}

Maksud dari penelitian ini adalah membuat Fitur Reminder Angsuran Pinjaman Anggota Menggunakan Sms Gateway pada Sistem Informasi Simpan Pinjam Berbasis Web di KPRI Mitra Setia Adapun tujuan dari penelitian ini yaitu:

- Mempermudah penyimpanan data agar tidak terjadi adanya penumpukan data.

- Mempermudah perhitungan simpanan, pinjaman dan angsuran menjadi lebih efisien dan efektif.

- Membantu mengingatkan

- Anggota dalam melakukan

- Pembayaran angsuran

- pinjaman.

\subsection{Batasan Masalah}

Agar pembahasan fitur reminder angsuran pinjaman anggota menggunakan sms gateway pada sistem informasi simpan pinjam berbasis web di KPRI Mitra Setia lebih terarah dan permasalahan yang dihadapi tidak melebar luas yang dapat menyita waktu banyak, maka permasalahan yang akan dibahas sebagai berikut:

- Pengelolaan data anggota.

- Transaksi simpan dan pinjam.

- Pengelolaan data pengurus.

- Laporan simpan pinjam.

- Notifikasi tanggal jatuh tempo pembayaran dengan sms gateway.

\section{Landasan Teori}

\subsection{Sistem Informasi}

Sistem informasi ialah interaksi antara data, manusia dan prosedur (yang didukung oleh hardware dan software) untuk memberikan suatu penyelesaian berupa informasi yang dapat dipakai untuk mengambil suatu tindakan keputusan selanjutnya baik untuk jangka pendek, menengah atau panjang dalam sebuah organisasi. Dengan kata lain, sistem informasi juga adalah suatu kumpulan dari komponen-komponen yang saling berinteraksi untuk mengelola informasi pada suatu organisasi untuk mendukung kegiatan bisnis organisasi. (Yulianto, 2012). Sistem informasi terdiri dari komponen-komponen yang disebut blok bangunan (building blok), yang terdiri dari komponen input, komponen model, komponen output, komponen teknologi, komponen hardware, komponen software, komponen basis data, dan komponen kontrol. Semua komponen tersebut saling berinteraksi satu dengan yang lain membentuk suatu kesatuan untuk mencapai sasaran. a. Komponen input

Input mewakili data yang masuk kedalam sistem informasi. Input disini termasuk metode dan media untuk menangkap data yang akan dimasukkan, yang dapat berupa dokumen dokumen dasar.

b. Komponen model

Komponen ini terdiri dari kombinasi prosedur, logika, dan model matematik yang akan memanipulasi data input dan data yang tersimpan di basis data dengan cara yag sudah ditentukan untuk menghasilkan keluaran yang diinginkan.

\section{c. Komponen output}

Hasil dari sistem informasi adalah keluaran yang merupakan informasi yang berkualitas dan dokumentasi yang berguna untuk semua pemakai sistem.

d. Komponen teknologi

Teknologi merupakan "tool box" dalam sistem informasi, Teknologi digunakan untuk menerima input, menjalankan model, menyimpan dan mengakses data, meghasilkan dan mengirimkan keluaran, dan membantu pengendalian dari sistem secara keseluruhan.

e. Komponen hardware

Hardware berperan penting sebagai suatu media penyimpanan vital bagi sistem informasi. Yang berfungsi sebagai tempat untuk menampung database atau lebih mudah dikatakan sebagai sumber data dan informasi untuk memperlancar dan mempermudah kerja dari sistem informasi.

f. Komponen software

Software berfungsi sebagai tempat untuk mengolah, menghitung dan memanipulasi data yang diambil dari hardware untuk menciptakan suatu informasi.

g. Komponen basis data

Basis data (database) merupakan kumpulan data yang saling berkaitan dan berhubungan satu dengan yang lain, tersimpan di perangkat keras komputer dan menggunakan perangkat lunak untuk memanipulasinya. Data perlu disimpan dalam basis data untuk keperluan penyediaan informasi lebih lanjut. Data di dalam basis data perlu diorganisasikan sedemikian rupa supaya informasi yang dihasilkan berkualitas. Organisasi basis data yang baik juga berguna untuk efisiensi kapasitas penyimpanannya. Basis data diakses atau dimanipulasi menggunakan perangkat lunak paket yang disebut DBMS (Database Management System).

h. Komponen control

Banyak hal yang dapat merusak sistem informasi, seperti bencana alam, api, temperatur, air, debu, kecurangan-kecurangan, kegagalan-kegagalan sistem itu 
sendiri, ketidak efisienan, sabotase dan lain sebagainya. Beberapa pengendalian perlu dirancang dan diterapkan untuk meyakinkan bahwa hal - hal yang dapat merusak sistem dapat dicegah atau pun bila terlanjur terjadi kesalahan-kesalahan dapat langsung cepat diatasi. (Fatta, 2007)

\subsection{Sms Gateway}

SMS Gateway adalah sustu sistem yang menjembatani antara handphone dengan sistem yang menjadi server dengan SMS sebagai informasinya. SMS Gateway tidak memerlukan koneksi internet manapun karena sifatnya memang bekerja sendirian (stand alone). SMS Gateway memerlukan satu atau beberapa buah terminal. Pemilihan banyak terminal akan menjadikan pengiriman dan penerimaan SMS semakin cepat.

Pada SMS Gateway, data yang dikirimkan ke telepon seluler peminta sebagai respon atas permintaan tersebut. Data-data yang disediakan oleh penyedia data dikelompokkan dengan kode-kode tertentu yang sudah distandarkan dan sudah terbentuk format tertentu yang disesuiakan dengan kemampuan SMS. Jadi peminta dapat memilih data mana yang diinginkan dengan mengirimkan kode tertentu yang sudah distandarkan tadi.

Komponen pendukung SMS Gateway antara lain :

a. PC atau laptop (sms server) yang digunakan untuk meletakkan aplikasi SMS Gateway dan admnistrasi yang akan dibangun.

b. Handphone (Receiver) yang digunakan untuk menerima sms dalam hal ini sms yang telah dikirim oleh handphone pemakai (orginator).

c. Handphone (Orginatur) yang digunakan untuk mengirimkan sms ke handphone (receiver).

d. Kabel data yang digunakan untuk pentransferan sms dari handphone (receiver) ke PC atau laptop dan sebaliknya. Bila menghubungkan ponsel melalui port serial tidak akan dapat terdeteksi secara otomatis oleh komputer. Jika menggunakan kabel data kestabilan koneksinya tidak akan terputus selama kabelnya tidak dicabut.

Keuntungan SMS Gateway antara lain :

a. Dapat menyebarkan pesan ke ratusan nomor secara otomatis dan cepat yang langsung terhubung dengan database nomor-nomor ponsel saja tanpa harus mengetik ratusan nomor dan pesan di ponsel karena semua nomor akan diambil secara otomatis dari database tersebut.

b. Dapat mengotomisasi pesan-pesan yang ingin dikirim. Dengan menggunakan program tambahan yang dapat dibuat sendiri, pengirim pesan dapat lebih fleksibel dalam mengirim berita karena biasanya pesan yang ingin dikirim berbeda-beda untuk masing-masing penerimanya.

Kekurangan SMS Gateway antara lain :

a. Jika terdapat gangguan pada jaringan telekomunikasi, maka sistem tidak dapat secara otomatis mengirim ulang pesan yang telah dikirimkan.

b. Tidak mendukung pengiriman sms dalam bentuk gambar dan suara melainkan dalam bentuk teks saja.
Beberapa fitur atau model yang umum dikembangkan dalam aplikasi SMS gateway adalah :

a. Auto Reply

SMS gateway secara otomatis akan membalas SMS yang masuk. Pengirim mengirimkan SMS dengan format tertentu yang dikenali aplikasi, kemudian aplikasi dapat melakukan auto-reply dengan membalas SMS tersebut, berisi informasi yang dibutuhkan.

b. Pengiriman Masal

Disebut juga dengan istilah SMS broadcast atau jenis sms satu arah ke banyak nomor tujuan yang bertujuan untuk mengirimkan SMS ke banyak tujuan sekaligus.

c. Pengiriman Terjadwal

Sebuah SMS dapat diatur untuk dikirimkan ke tujuan secara otomatis pada waktu tertentu. Contohnya untuk keperluan mengucapkan selamat ulang tahun.

\section{Analisis Dan Perancangan Sistem 3.1 Analisis Pengguna}

Analisis pengguna menunjukan siapa saja yang terlibat dalam Aplikasi Pengelolaan simpan pinjam, serta hak akses apa saja dalam perangkat lunak tersebut. Aplikasi yang dibangun memiliki dua pengguna, yaitu :

a. Anggota

Anggota merupakan pengunjung dari aplikasi pengelolaan simpan pinjam ini. Anggota bisa melihat data simpan anggota yang sudah masuk pada aplikasi ini.

b. Admin Sistem

Admin sistem adalah orang yang bertanggung jawab untuk mengelola semua data pada aplikasi.

\subsection{Analisis Kebutuhan Fungsional}

Kebutuhan fungsional menjelaskan mengenai prosesproses apa saja yang akan dilakukan oleh sistem. Deskripsi dari kebutuhan aktivitas-aktivitas dan layananlayanan yang harus disediakan oleh sistem, kebutuhan fungsional sistem menggambarkan layanan secara detail. Berikut adalah fungsi atau modul yang dibutuhkan oleh sistem yang nantinya akan digunakan oleh user (pengguna).

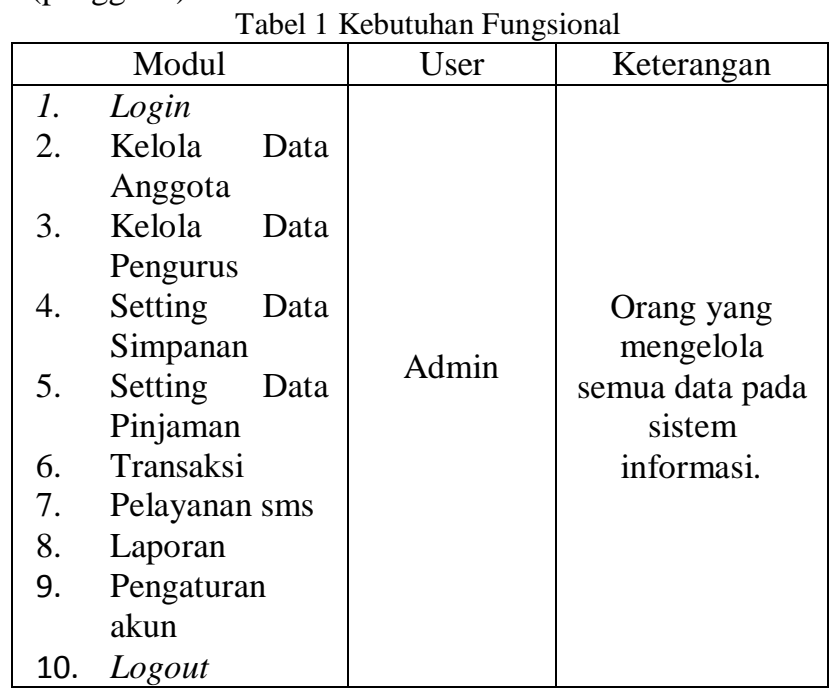




\subsection{Use Case Diagram}

Use Case diagram memperlihatkan tiga aspek sistem yaitu aktor, Use Case, dan lingkup sistem / sub sistem. Memperlihatkan hubungan antara aktor dan fungsi yang dapat dilakukan oleh aktor dalam ruang lingkup sistem

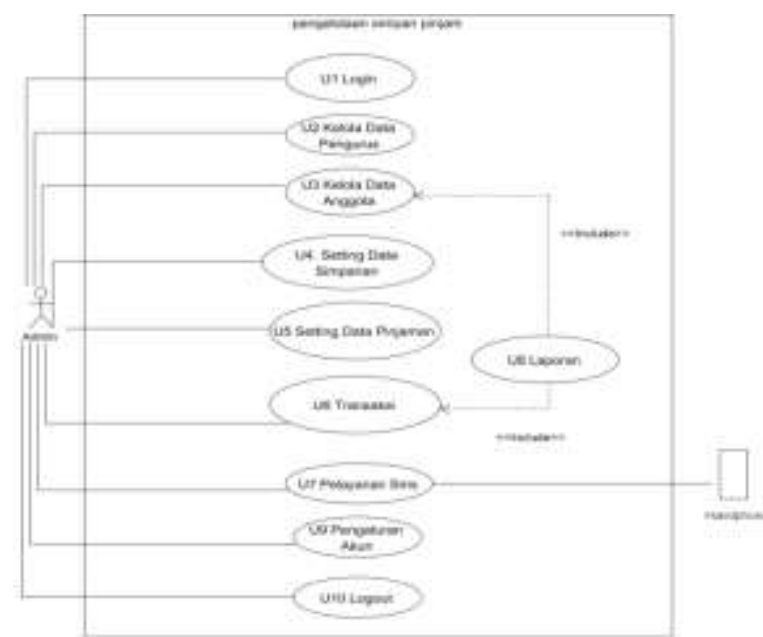

Gambar 1 Use Case Diagram Sistem Informasi Simpan Pinjam Di KPRI Mitra Setia

Berdasarkan Gambar 3.1 Use Case Diagram Sistem Informasi Simpan Pinjam, terdapat 1 aktor yaitu Admin dan ada handphone sebagai penerima sms, dan juga terdapat 10 Use Case yaitu Admin terlebih dahulu harus melakukan login kemudian mendapatkan hak akses terhadap Sistem Informasi Simpan Pinjam mulai dari kelola data pengurus, kelola data anggota, setting data simpanan, setting data pinjaman, transaksi, pelayanan sms, laporan, pengaturan akun, logout.

\subsection{Class Diagram}

Diagram kelas atau class diagram menggambarkan struktur sistem dari segi pendefinisian kelas-kelas yang akan dibuat untuk membangun sistem. Kelas memiliki apa yang disebut atribut dan metode atau operasi

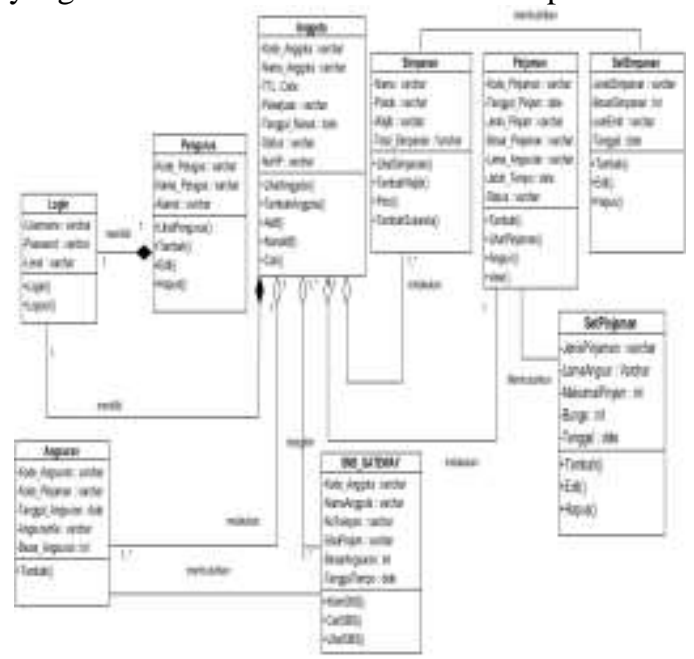

Gambar 2 Class Diagram Sistem Informasi Simpan Pinjam Di KPRI Mitra Setia

Terdapat 9 class yang terdiri dari class login, pengurus, anggota, simpanan, pinjaman, angsuran, sms gateway, laporan, setsimpanan, setoinjaman dan masingmasing class mempunyai relasi

\section{Antarmuka Sistem.}
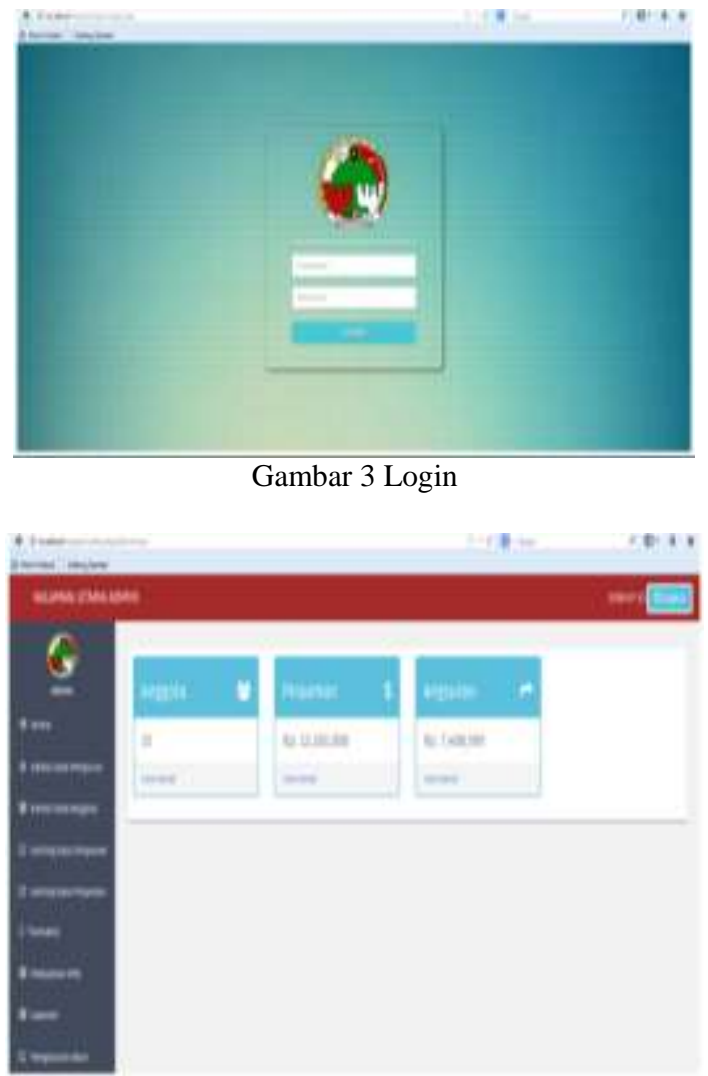

Gambar 4 Halaman utama admin

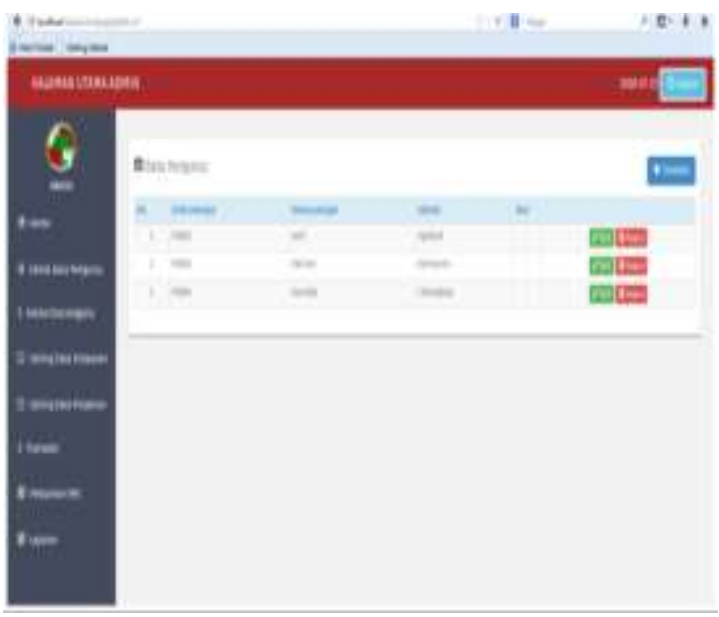

Gambar 5 Halaman Kelola Data Pengurus

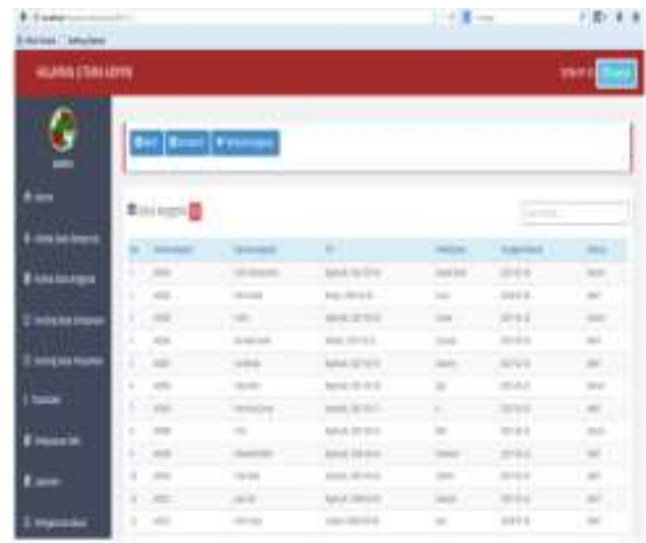

Gambar 6 Halaman Data Anggota 
Ai Musrifah ${ }^{1}$, Eneng Siti Sa'adah ${ }^{2}$, Fitur Reminder Angsuran Pinjaman Anggota Menggunakan Sms Gateway Pada Sistem Informasi Simpan Pinjam Berbasis Web Di KPRI Mitra Setia

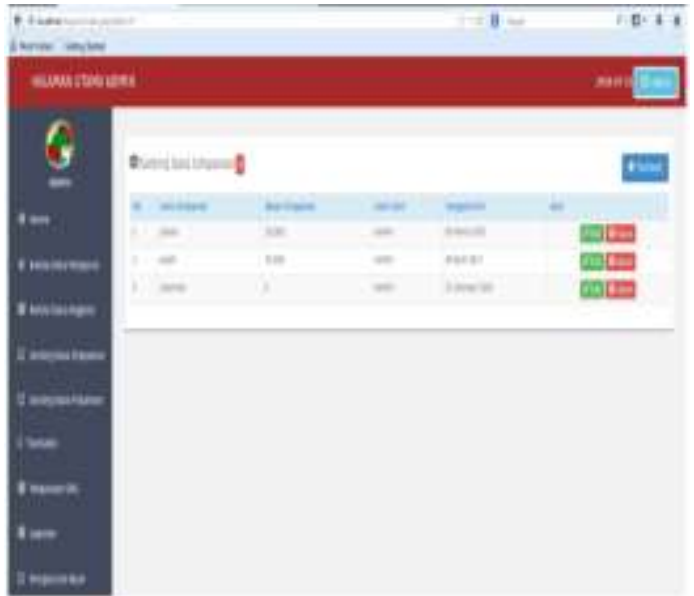

Gambar 7 Halaman Setting Data Simpanan

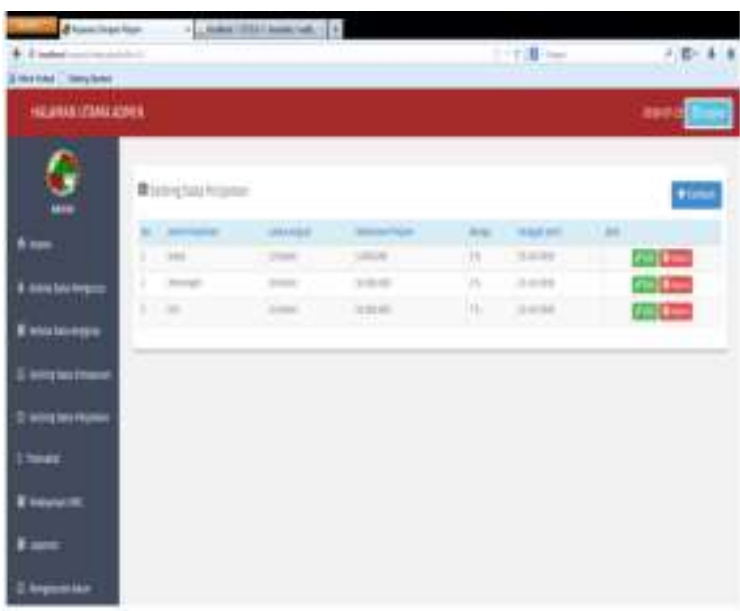

Gambar 8 Halaman Setting Data Pinjaman

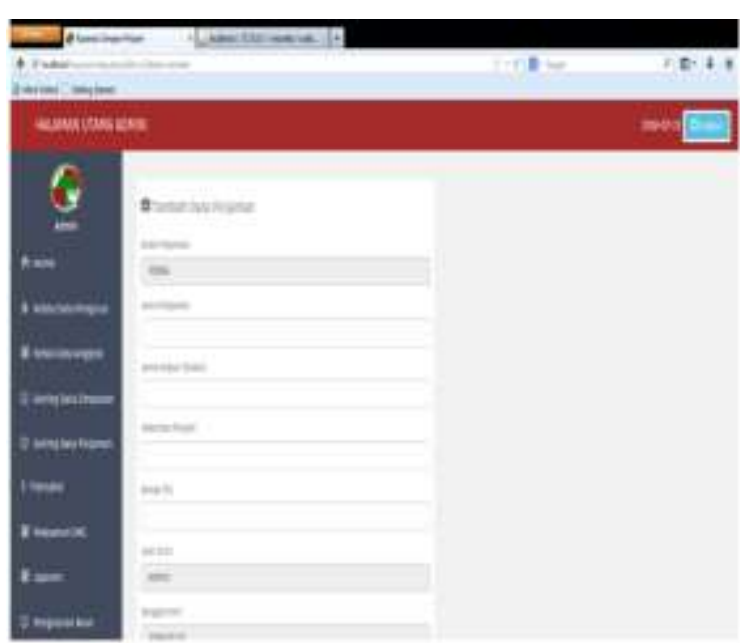

Gambar 9 Halaman Tambah Setting Pinjaman

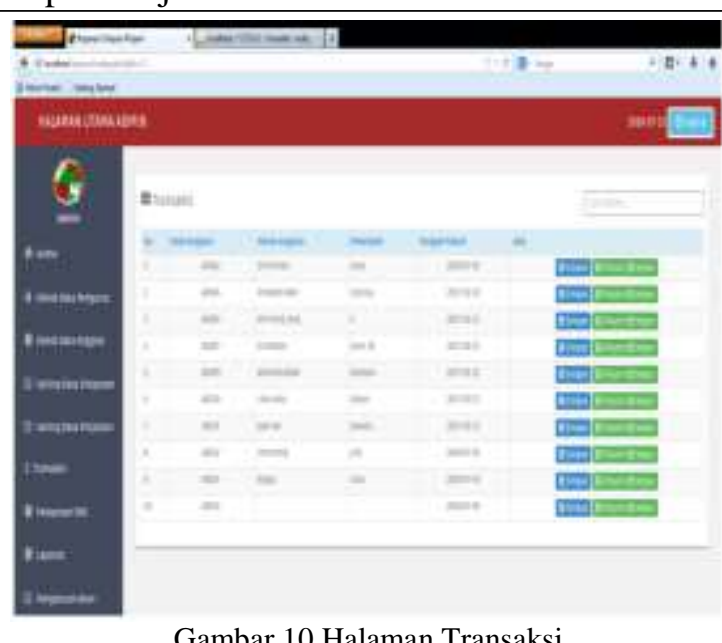

Gambar 10 Halaman Transaksi

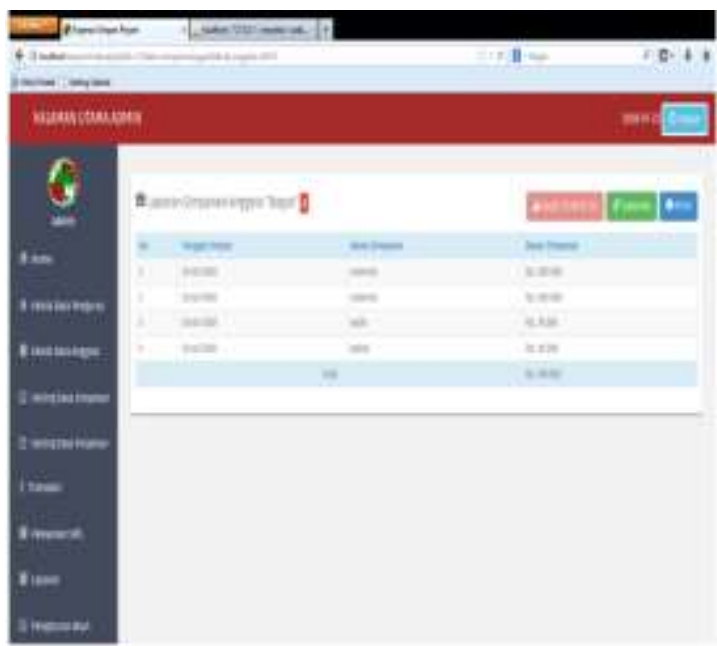

Gambar 11 Halaman Simpanan

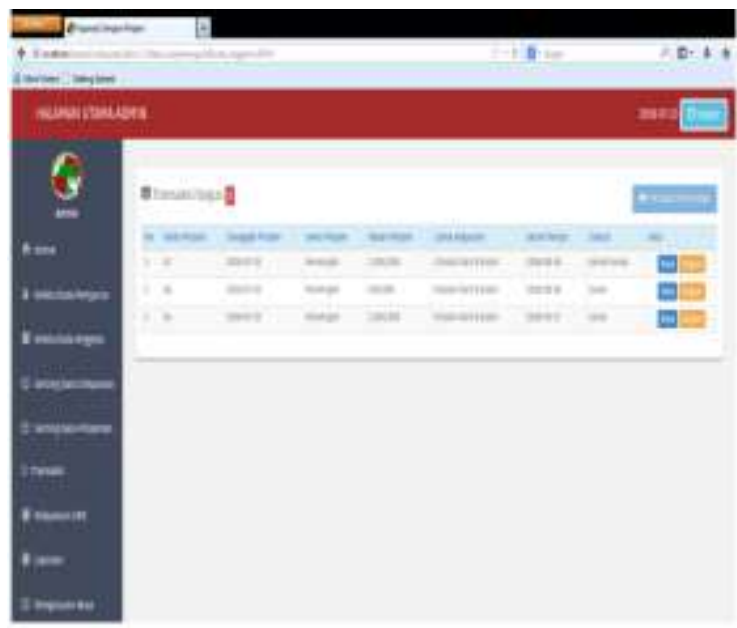

Gambar 12 Halaman Pinjam Angsur

\section{Simpulan}

Dari hasil penelitian, perancangan dan implementasi yang telah dilakukan penulis dapat menyimpulkan beberapa hal sebagai berikut :

a. Telah dibangun sebuah fitur reminder angsuran pinjaman anggota menggunakan sms gateway pada sistem informasi simpan pinjam berbasis web di 
KPRI Mitra yang dapat memudahkan dalam mengelola data simpan pinjam

b. Sistem Informasi ini dapat mempermudah penyimpanan data agar tidak terjadi adanya penumpukan data.

c. Sistem Informasi ini dapat mempermudah perhitungan simpanan, pinjaman dan angsuran menjadi lebih efisien dan efektif.

d. Sistem Informasi dengan fitur reminder ini dapat membantu mengingatkan anggota dalam melakukan pembayaran angsuran pinjaman.

\section{Saran}

Untuk meningkatkan kinerja sistem informasi simpan pinjam berbasis web dengan fitur reminder untuk pengelolaan angsuran pinjaman anggota koperasi di KPRI Mitra Setia, maka penulis mengajukan beberapa saran antara lain :

a. Untuk pengembangan selanjutnya dapat dibuatkan aplikasi berbasis mobile sehingga anggota dapat melakukan transaksi secara online.

b. Sebaiknya sistem dapat melakukan pengiriman pemberitahuan sesuai jadwal jatuh tempo.

\section{Daftar Pustaka}

[1] A.M, Z. (2012). Manajemen Sistem Informasi. Jakarta: Gramedia Pustaka Utama.

[2] Anhar. (2010). Panduan Menguasai PHP \& MySQL Secara Otodidak. Jakarta: Mediakita.

[3] Aryanto. (2016). Soal Latihan dan Jawaban Pengolahan Database MySQL Tingkat Dasar. Yogyakarta.

[4] Atmosudirdjo, P. (1983). Hukum Administrasi Negara. Jakarta: Ghalia Indonesia.

[5] Ayuliana. (2009, Maret). Teknik Pengujian Perangkat Lunak. Retrieved from http://rifiana.staff.gunadarma.ac.id/:

http://rifiana.staff.gunadarma.ac.id/Downloads/file s/26083/Teknik+Pengujian+perangkat+Lunak++ Black+Box.pdf

[6] Ciloto, B. B. (2012). Balai Besar Pelatihan Kesehatan (BBPK) Ciloto. Retrieved from Balai Besar Pelatihan Kesehatan (BBPK) Ciloto: http://bbpkciloto.or.id/index.php?halaman=visimisi

[7] Dantha, R. (2009 : 32). Pengantar Ilmu Komputer. Surabaya: Indah.

[8] Efraim Turban, J. E. (2005). Decision Support System and Intelligent System Edisi 7. Yogyakarta: Andi.

[9] Fathansyah. (2012). Basis Data. Bandung: Informatika Bandung.

[10] Fatta, H. A. (2007). Analisis dan Perancangan Sistem Informasi.

[11] Irmansyah, F. (2003). pengantar Database.

[12] Jeperson, H. (2014). Konsep Sistem Informasi. Yogyakarta: CV BUDI UTAMA.

[13] Jogiyanto, H. (1999 : 2). Pengenalan Komputer. Yogyakarta: Andi.

[14] Jogiyanto, H. (2005). Sistem Teknologi Informasi. Yogyakarta: Andi Offset.

[15] Kurikulum. (2004). Standar Kompetensi Sekolah Dasar. Jakarta: Depdiknas.
[16] Kusumadewi Sri, d. (2006). Fuzzy Multi-Attribute Decision Making (Fuzzy MADM). Yogyakarta: GRAHA ILMU.

[17] Pressman, R. S. (2010). Rekayasa Perangkat Lunak. Yogyakarta: Andi.

[18] Roger S Pressman. (2010). Rekayasa Perangkat Lunak. Yogyakarta: Pendekatan Praktisi Edisi 7.

[19] Rudianto. (2010). Akuntansi Koperasi Edisi Kedua. Jakarta: Erlangga.

[20] Saifuddin. (2014). Pengelolaan Pembelajaran Teoritis dan praktis. Yogyakarta.

[21] Siagian, S. P. (1997). Manajemen Sumbaer Daya Manusia. Jakarta: PT. Toko Gunung Agung.

[22] Simarmata, J. (2010). Rekayasa Perangkat Lunak. Yogyakarta: CV ANDI OFFSET.

[23] Soemanto, H. S. (1982). kepemimpinan dalam pendidikan.

[24] Supardi, I. (2007). Sistem Penjualan Service.

[25] Whitten, L. J. (2004). Metode Desain \& Analisis Sistem. Yogyakarta: ANDI.

[26] Yulianto, A. A. (2012). Analisis dan Desain Informasi. Yogyakarta: Andi. 